\title{
Experimental Investigation of the Technical Performances of SRX-Stabilized Graded Macadam
}

\author{
Na Xu, ${ }^{1}$ Zhongda Chen ${ }^{D},{ }^{1}$ Haijun Gao, ${ }^{2}$ Dingming Dong, ${ }^{2}$ Yongjun Wu, ${ }^{3}$ Guanghui Lu, ${ }^{4}$ \\ and Zhifeng Chen ${ }^{5}$ \\ ${ }^{1}$ Key Laboratory for Special Area Highway Engineering of Ministry of Education, Chang'an University, Xi'an 710064, China \\ ${ }^{2}$ Yan'an Highway Administration Bureau, Yan'an 716099, China \\ ${ }^{3}$ Weinan Traffic Bureau of Shaanxi Province, Weinan 714000, China \\ ${ }^{4}$ Highway Survey and Design Institute of Zhoukou, Zhoukou 466000, China \\ ${ }^{5}$ Henan Hongsheng Engineering Supervision Co. Ltd., Zhoukou 466000, China
}

Correspondence should be addressed to Zhongda Chen; 2019021099@chd.edu.cn

Received 10 March 2021; Revised 18 August 2021; Accepted 25 August 2021; Published 14 September 2021

Academic Editor: José António Fonseca de Oliveira Correia

Copyright (c) $2021 \mathrm{Na} \mathrm{Xu}$ et al. This is an open access article distributed under the Creative Commons Attribution License, which permits unrestricted use, distribution, and reproduction in any medium, provided the original work is properly cited.

\begin{abstract}
The technical performances of Solution Road RomixSoilfix- (SRX-) stabilized graded macadam (SSGM) are investigated to promote its application. The specimen curing conditions were proposed to improve the test efficiency by analyzing the influence of curing temperature on the unconfined compressive strength and moisture content variation. Moreover, the mechanical properties (e.g., CBR, strength, and resilient modulus) and pavement performances (e.g., temperature shrinkage, water stability, and freezing stability) of SSGM were evaluated through laboratory tests. The results show that the recommended curing temperature in the drying oven should be $100^{\circ} \mathrm{C} \pm 2^{\circ} \mathrm{C}$ and the recommended curing time should not be less than $16 \mathrm{~h}$. Furthermore, the CBR, unconfined compressive and splitting strengths, and resilient modulus of SSGM increase with the content of SRX stabilizer. The temperature shrinkage coefficient is approximately $15 \%$ of the cement-stabilized grading crushed stone. The dry-wet recovery strength ratio is approximately $96 \%$ after four dry-wet cycles. The freeze-thaw recovery strength ratio is approximately $58 \%$ after five freeze-thaw cycles. The freezing stability of SSGM can be improved by increasing the content of SRX stabilizer. The technical performances of SSGM should fulfill the technical requirements.
\end{abstract}

\section{Introduction}

Semirigid materials are widely used in the pavement base of high-grade highways in China $[1,2]$. Semirigid base with high strength and good slab property can effectively improve the bearing capacity of asphalt pavements [3-5]. However, simirigid base has its own insurmountable shortcomings, e.g., dry shrinkage, temperature shrinkage, and reflective cracking. Moreover, the stability, durability, and service life of the pavement structure are damaged due to the combined effect of load, climate, and moisture [6-9]. In China, the research and application of flexible bases have attracted the attentions from a considerable number of scholars [10-12]. Common flexible bases mainly include asphalt-stabilized macadam base and graded macadam base [13-16].
Additionally, Solution Road RomixSoilfix (SRX) used as a new road material has become a research hotspot among flexible bases. SRX is an organic copolymer solution comprising a variety of special resins and organic additives. SRXstabilized graded macadam (SSGM) is a mixture of crushed stones and SRX. A thin layer of organic mucosa is formed on the surface of the crushed stone particles due to the evaporation of light components and water [17]. A strong layer formed by adhesion between the SRX and crushed stones effectively inhibits the formation of cracks in the structural layer [18]. Therefore, SSGM with a strong flexible structure can be effectively used to solve the problems of reflective and fatigue cracks in the base. SSGM also has certain advantages in application conditions, technical quality, construction technology, construction conditions, and economic benefits 
[19]. In past decades, many scholars have performed extensive researches on its technical performance and conducted its exploratory applications in some countries. Iyengar et al. studied the SRX for application in highway pavement base and analyzed the feasibility of SRX based on the local engineering practice in Qatar [20]. Scholten et al. found that the SRX-stabilized material can significantly improve the pavement performance and reduce the overall pavement thickness by comparing with ordinary semirigid base asphalt pavement [21]. Since 2008, SRX-stabilized materials have been used in Beijing, Guangdong Province, Liaoning Province, and Sichuan Province in China. Zhang et al. studied and analyzed the mechanical properties of SRX-stabilized base materials and the mechanical response of asphalt pavement structures [22]. It is found that SRXstabilized materials used as pavement base have good fatigue resistance. Meanwhile, Du compared and analyzed the properties of SRX-stabilized materials and inorganic binder stabilized materials. It was proved that the SRX-stabilized materials have advantages such as superior mechanical properties, improvement of fatigue life, and crack resistance [23].

The abovementioned studies have promoted the development and application of SSGM. However, there are few studies on the systematical investigation on the mechanical properties and pavement performances of SSGM. Furthermore, an appropriate curing condition with short test period for SSGM specimen is rarely reported. For instance, Romix International Ltd. suggested that the curing condition of a SSGM specimen is as follows: (1) the specimen is cured in an oven at $50^{\circ} \mathrm{C}$ for 2 days, and then the specimen is dried in the sun for 7 days again; (2) the specimen is directly cured in an oven at $30^{\circ} \mathrm{C}$ for 10 days [19]. However, the above curing condition affects the experimental process and reduces the experimental efficiency with the increase in the amount of specimens in the experiment.

Hence, this paper aims to explore the appropriate curing conditions of SSGM based on the effect of curing temperature and curing time on the formation of unconfined compressive strength and moisture content variation. Meanwhile, the mechanical properties and road performance of SSGM are evaluated to provide technical support for engineering applications.

\section{Test Materials}

2.1. SRX Stabilizers and Graded Macadam. The raw materials of SSGM comprise the SRX stabilizer, aggregates, and water. The SRX stabilizer is obtained from Romix International Ltd. and its technical performances are presented in Table 1. Limestone aggregate produced in Weinan, Shaanxi Province, is selected as the aggregate. The technical performance of aggregate was tested according to Test Methods of Aggregate for Highway Engineering (JTG E42-2005) [24]. All indicators conform with the relevant requirements listed in Technical Guidelines for Construction of Highway Roadbases (JTG/T F20-2015) [25], as shown in Table 2.
2.2. SSGM Mixture. The SSGM consists of aggregate, SRX stabilizer, and water. The aggregate gradation is obtained based on the multistage crowded skeleton determined by the previous study of the research group. The gradation design methods are as follows: (1) the step-by-step filling theory is used to determine the gradation of coarse aggregates on the basis of interference theory [26]. (2) The gradation of fine aggregates is determined by using I method according to the maximum density curve theory $[27,28]$. (3) The proportion of coarse aggregates and fine aggregates is rest with the double-optimum principle of dry density and unconfined compressive strength [29]. The composite gradation is presented in Table 3. The optimum moisture content and maximum dry density of SSGM determined by the vibratory compaction test (T0133-1993) in Test Method of Soils for Highway Engineering (JTG E40-2007) were 3.40\% and $2.47 \mathrm{~g} / \mathrm{cm}^{3}$, respectively [30]. The content of SRX stabilizer was initially $0.25 \%, 0.5 \%, 0.75 \%$, and $1 \%$.

\section{Experimental Procedure}

3.1. Curing Condition Test. A cylindrical test specimen of $\varphi 150 \mathrm{~mm} \times 150 \mathrm{~mm}$ under the compaction of $98 \%$ was formed by referring to the specification (T 0843-2009) in Test Methods of Materials Stabilized with Inorganic Binders of Highway Engineering (JTG E51-2009) [31]. The SSGM specimens were divided into ten groups. Nine groups were cured in an oven at $30^{\circ} \mathrm{C}, 50^{\circ} \mathrm{C}, 65^{\circ} \mathrm{C}, 80^{\circ} \mathrm{C}, 90^{\circ} \mathrm{C}, 95^{\circ} \mathrm{C}, 100^{\circ} \mathrm{C}$, $105^{\circ} \mathrm{C}$, and $110^{\circ} \mathrm{C}$, whereas the remaining group was cured under natural conditions for 45 days (the test was performed in July, 2019; the average temperature is $30^{\circ} \mathrm{C}$ ).

The curing time of nine groups of specimens was determined by recording the change of water content with time. The methods were according to the Drying Method ( $\mathrm{T}$ 0801-2009) in Test Methods of Materials Stabilized with Inorganic Binders of Highway Engineering (JTG E51-2009) [31], until the moisture content was zero, indicating that all the samples were completely dry. Meanwhile, the SSGM specimen cured for 45 days under natural conditions was selected as the benchmark while the strength of the specimen was selected as the benchmark strength. The nine specimen groups were then tested for unconfined compressive strength after they were cured in the oven.

\subsection{Mechanical Performance Test}

3.2.1. California Bearing Ratio (CBR) Test. California Bearing Ratio (CBR) is used to verify the bearing capacity of SSGM. The CBR test (T0134-1993) was performed by the Test Method of Soils for Highway Engineering (JTG E40-2007) [30]. A cylindrical test specimen of $\varphi 152 \mathrm{~mm} \times \mathrm{h}$ $170 \mathrm{~mm}$ was formed under the given conditions as follows: the compaction of the specimens is $98 \%$; the moisture content and dry density are optimum and maximum, respectively; the contents of SRX stabilizer were $0 \%, 0.25 \%$, $0.5 \%, 0.75 \%$, and $1 \%$. The cured specimens were soaked in normal temperature water for $96 \mathrm{~h}$, and then the CBR of the specimens were measured under the most unfavorable conditions. 
TABLE 1: Technical performances of the SRX stabilizer.

\begin{tabular}{lccccccc}
\hline Index & Solid amount $(\%)$ & $\mathrm{pH}$ & Viscosity $(\mathrm{cps})$ & Boiling point $\left({ }^{\circ} \mathrm{C}\right)$ & Proportion & Flammability & Water-soluble \\
\hline Detection value & 29.33 & 9 & 78.6 & 97 & 1.02 & Nonflammable & Soluble \\
Technical requirement & $28.5-31.5$ & $8-9$ & $50-100$ & $\approx 100$ & $>1$ & Nonflammable & Soluble \\
\hline
\end{tabular}

TABle 2: Technical performances of the aggregate.

\begin{tabular}{lccc}
\hline Technical indicators (\%) & Test result & Normative standard & Test code \\
\hline Crushing value & 17.6 & $\leq 22$ & T0316 \\
Acicular content & 7.4 & $\leq 18$ & T0312 \\
$\leq 0.075$ mm particle content (water-washing) & 0.9 & $\leq 1.2$ & T0310 \\
Clay content of fine aggregates & 2.1 & $\leq 3$ & T0333 \\
Soft stone content & 1.6 & $<3$ & T0320 \\
\hline
\end{tabular}

TABle 3: Aggregate gradation.

\begin{tabular}{lccccccc}
\hline Size of sieves $(\mathrm{mm})$ & 31.5 & 19 & 9.5 & 4.75 & 2.36 & 0.6 & 0.075 \\
\hline Gradation $(\%)$ & 100 & 64 & 47 & 36 & 28 & 17.5 & 7.5
\end{tabular}

The ratio of unit pressure to standard pressure was selected as the CBR value when the penetration of the materials was $2.5 \mathrm{~mm}$, as shown in Figure 1. The CBR is expressed by

$$
\mathrm{CBR}=\frac{P}{7000} \times 100 \%,
$$

where CBR represents bearing ratio and $P$ denotes unit pressure.

\subsubsection{Unconfined Compressive Strength and Splitting} Strength Tests. Unconfined compressive strength (UCS) is the ultimate strength against the axial pressure under the given condition as follows: the deformation rate remains unchanged; the specimen is continuously loaded without lateral pressure until it is damaged. A cylindrical test specimen of $\varphi 150 \mathrm{~mm} \times 150 \mathrm{~mm}$ was molded by the compaction of $98 \%$. The contents of SRX stabilizer were $0 \%$, $0.25 \%, 0.5 \%, 0.75 \%$, and $1 \%$. The UCS test (T 0805-1994) was performed by referring to Test Methods of Materials Stabilized with Inorganic Binders of Highway Engineering (JTG E51-2009) [31]. Figure 2 shows the unconfined compressive strength test [23]. The unconfined compressive strength $(R)$ is calculated using the following equation:

$$
R=\frac{P}{A}
$$

where $P$ is the maximum pressure when the specimen is damaged and $A$ is the cross-sectional area of the test specimen; $A=\pi D^{2} / 4$, where $D$ is the diameter of the test specimen.

Splitting strength is an indirect bending tensile strength. It is also a maximum stress that the specimen can bear before breaking. The splitting strength test (T 0806-1994) should be carried out in accordance with Test Methods of Materials Stabilized with Inorganic Binders of Highway Engineering (JTG E51-2009) [31]. The test specimen used in the splitting strength test is the same as that of the unconfined compressive strength test. Meanwhile, the SRX stabilizer contents of SSGM were $0.25 \%, 0.5 \%, 0.75 \%$, and $1 \%$. Figure 3 shows the apparatus of the splitting strength test. The splitting strength $(r)$ is calculated using the following equation:

$$
r=\frac{2 p}{\pi d h}
$$

where $p$ is the maximum pressure value when the test specimen is damaged, $d$ is the diameter of the test specimen, and $h$ is the height of the test specimen.

3.2.3. Compressive Modulus of the Resilience Test. Compressive modulus of resilience test (T 0808-1994) was performed by referring to Test Methods of Materials Stabilized with Inorganic Binders of Highway Engineering (JTG E51-2009) [31]. The selected unit pressure was divided into 4-6 levels as the stress value of each loading level. The test is used to determine the pressure that the material can bear in the elastic range determined by the level-by-level loading and unloading test. The measured compressive modulus of resilience is used to characterize the mechanical properties of the specimen in the elastic stage. The testing equipment used in the compressive modulus of resilience test is shown in Figure 4. The compressive modulus of resilience $\left(E_{w}\right)$ is calculated using the following equation:

$$
E_{w}=\frac{p H}{l}
$$

where $P$ is the unit pressure, $H$ is the height of the test specimen, and $l$ is the rebound deformation of the test specimen (i.e., the difference between the load and unload reading data).

\subsection{Pavement Performance Test}

3.3.1. Temperature Shrinkage Performance. The temperature shrinkage test of the material was performed by using a tester of pavement material shrinkage deformation, as shown in Figure 5. First, the conditions required for the test in the host machine were set and the test specimen was inserted into the environment box for fixed installation. Then, the computer was used to control the temperature in the environment box 


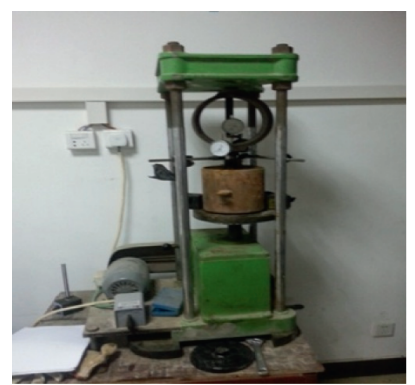

Figure 1: CBR test.

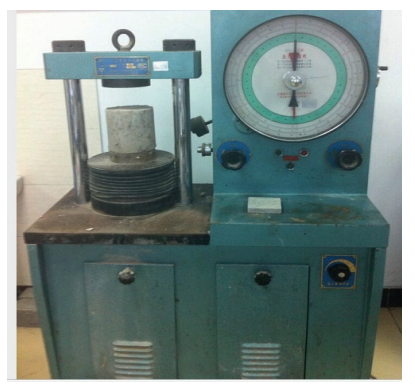

FIGURE 2: Unconfined compressive strength test.

according to the setting conditions. The data were collected by a displacement sensor, and the received data signals were transmitted to the computer through A/D converter. Finally, the data was automatically processed by the computer based on the internal program. The results of temperature shrinkage test were therefore obtained [32].

The gradation of SSGM is presented in Table 3, and the contents of SRX stabilizer were $0.25 \%, 0.5 \%, 0.75 \%$, and $1 \%$. The beam specimen of size $100 \times 100 \times 400 \mathrm{~mm}^{3}$ was molded by the compaction of $98 \%$ after standard curing. The temperature ranges were divided into six parts: $40^{\circ} \mathrm{C}-30^{\circ} \mathrm{C}, \quad 30^{\circ} \mathrm{C}-20^{\circ} \mathrm{C}, \quad 20^{\circ} \mathrm{C}-10^{\circ} \mathrm{C}, \quad 10^{\circ} \mathrm{C}-0^{\circ} \mathrm{C}$, $0^{\circ} \mathrm{C}--10^{\circ} \mathrm{C}$, and $-10^{\circ} \mathrm{C}--20^{\circ} \mathrm{C}$. Moreover, the rate of temperature change in each part was $-10^{\circ} \mathrm{C} / \mathrm{h}$. Then, the specimens were preserved in each temperature range for $6 \mathrm{~h}$ under a constant temperature. Meanwhile, the interval of data acquisition was $5 \mathrm{~min}$. The specific steps are given as follows:

(1) The prepared beam test specimen was cured in an oven at $100^{\circ} \mathrm{C}$ until it was completely dry (Figure 6).

(2) Appropriate sizes of the glass specimens were placed on two square sides of the test specimen in order to ensure the accuracy of the collected data; and then test specimens were placed into the environment box of the tester; meanwhile, the displacement sensor receiving bar above the environment box was adjusted to its initial displacement. Figure 7 shows the working diagram of the tester environment box.

(3) The test parameters and data acquisition conditions were firstly set in the computer. And then the test started when the temperature in the environment box rose to $40^{\circ} \mathrm{C}$.

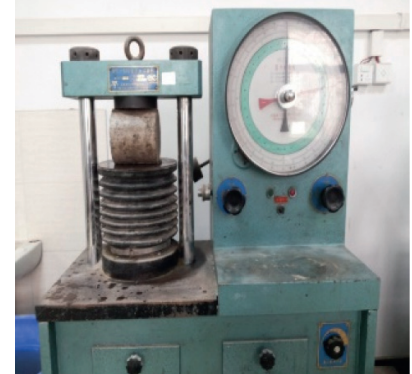

Figure 3: Splitting strength test.

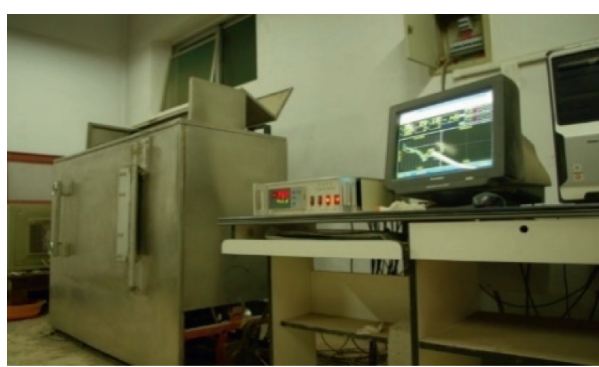

FIGURE 4: Compressive modulus of resilience test.

The displacement of each temperature range can be calculated, i.e., the temperature shrinkage deformation of the test specimen (e.g., the temperature from $T_{i}$ to $T_{i+1}$ and the corresponding displacement values from $\varepsilon_{i}$ to $\varepsilon_{i+1}$ ). The corresponding temperature shrinkage coefficient $\left(\alpha_{t i}\right)$ is therefore calculated using the following equation:

$$
\alpha_{t i}=\frac{\left(\varepsilon_{i+1}-\varepsilon_{i}\right)}{\left(T_{i+1}-T_{i}\right)}=\frac{\Delta \varepsilon}{\Delta T},
$$

where $\Delta T$ is the temperature difference and $\Delta \varepsilon$ is the temperature shrinkage corresponding to the temperature range.

3.3.2. Water Stability Performance. Water stability performance of SSGM was tested and evaluated through the drywet cycling test. The cylindrical test specimen of size $\varphi 150 \mathrm{~mm} \times 150 \mathrm{~mm}$ was molded by the compaction of $98 \%$. The prepared test specimens according to the specifications were divided into groups I, II, III, and IV, and each group was further divided into groups A and B [31]. Groups I, II, III, and IV were used for the first, second, third, and fourth dry-wet cycling tests, respectively.

The first group of specimens were taken as an example, and the specific test steps were as follows. The unconfined compressive strength and splitting strength of group I-A were tested after the standard curing. Then, the remaining specimens were immersed in water for $24 \mathrm{~h}$, and the liquid level was kept at $2 \mathrm{~cm}$ higher than the specimens. Thereafter, the unconfined compressive strength and splitting strength of group I-B were tested. The remaining groups of the specimens were cured under standard curing condition, and the following steps were similar to those of the first group. The unconfined compressive strength of specimen A of each 


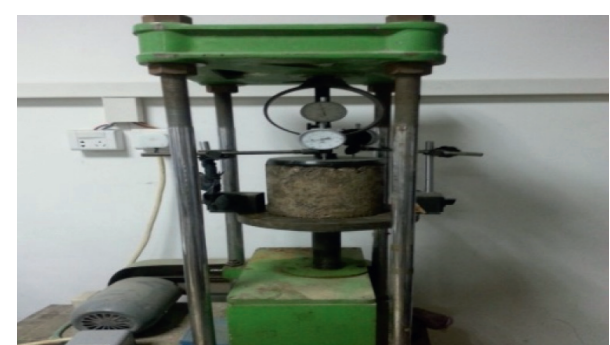

FIgURE 5: Pavement material shrinkage deformation tester.

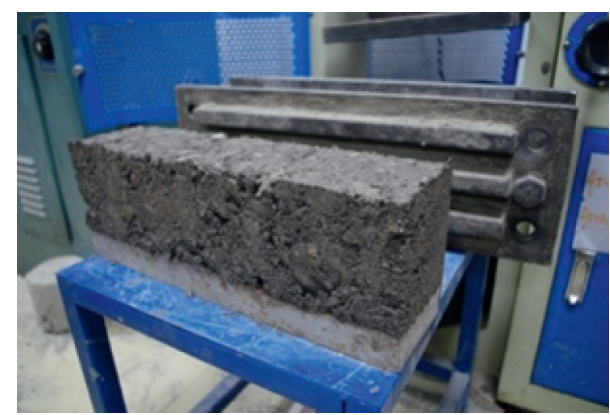

FIgURe 6: Isostatic pressure forming.

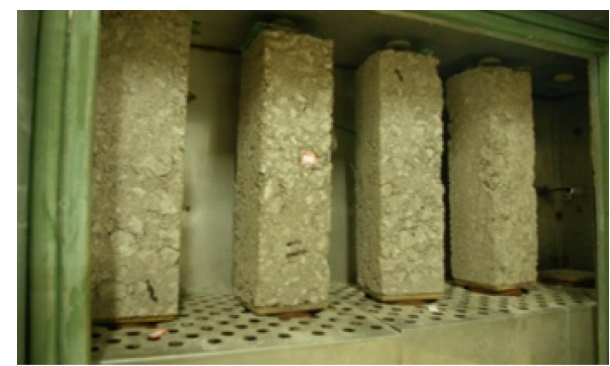

Figure 7: Working of the tester environment box of the beam specimen.

group was then tested. Furthermore, the unconfined compressive strength of specimen B was tested after immersion in water for $24 \mathrm{~h}$.

Meanwhile, the softening coefficient and dry-wet recovery strength ratio were used as indexes. The softening coefficient indicating the antiwater invasion ability of the materials is defined as the ratio of wet strength to dry strength. Furthermore, the dry-wet recovery strength ratio expressed as a percentage to reflect the strength recovery of the specimens after soaking and drying is defined as the ratio of the strength of immersed and redried specimens to that of nonimmersed specimens.

3.3.3. Freezing Stability Performance. The SSGM may be damaged by freeze-thaw during service due to the obvious seasonal alternation in northern China [33]. The specimens used in the freeze-thaw cycling tests are the same as those used in the water stability performance test. The freeze-thaw cycling tests are performed by referring to the test method for the freeze-thaw test of inorganic binders (T 0858-2009) in Test Methods of Materials Stabilized with Inorganic
Binders of Highway Engineering (JTG E51-2009) [31]. The prepared test specimens after standard curing were divided into six groups below: I, II, III, IV, V, and VI. Each group was separated into part A and part B, e.g., I-A and I-B. A freezethaw cycle process is described as follows: specimens were first soaked in water for $24 \mathrm{~h}$; specimens were then frozen at $-18^{\circ} \mathrm{C}$ for $16 \mathrm{~h}$; specimens were finally placed in a constant temperature water tank at a temperature of $20^{\circ} \mathrm{C}$ for $8 \mathrm{~h}$. Six groups of specimens were used for five freeze-thaw cycles. Part A and part B were used to analyze the unconfined compressive strengths of the specimens after the freeze-thaw process and standard curing under dry condition, respectively. The specific test steps were as follows: (1) the test specimens were divided into twelve parts after the standard curing, i.e., I-A, I-B, II-A, II-B, III-A, III-B, IV-A, IV-B, V-A, $\mathrm{V}-\mathrm{B}, \mathrm{VI}-\mathrm{A}$, and VI-B. The unconfined compressive strength of group I-B was tested. Then the unconfined compressive strength of I-A was tested after the remaining specimens have soaked in a constant temperature water tank for $24 \mathrm{~h}$. (2) The water on the surface of the specimens was wiped off; and then the specimens were frozen at $-18^{\circ} \mathrm{C}$ for $16 \mathrm{~h}$; afterwards, the specimens were placed in a constant temperature water tank at $20^{\circ} \mathrm{C}$ for $8 \mathrm{~h}$; the above process is the first freeze-thaw process. (3) The unconfined compressive strengths of group II-A were measured after the first freezethaw cycle; the unconfined compressive strengths of group II-B were measured after the standard curing of the first freeze-thaw cycle. (4) The remaining four groups of specimens were used for the second, third, fourth, and fifth freeze-thaw cycles, respectively. (5) Each freeze-thaw cycle was carried out by using the similar approach of the first freeze-thaw cycle.

The freeze-thaw coefficient and recovery strength ratio are the indexes for the freezing stability of SSGM. The freezethaw coefficient indicating the freezing resistance of the SSGM is defined as the ratio of freezing strength to dry strength. The freeze-thaw recovery strength ratio expressed as a percentage to reflect the recovery strength of the freezethaw redrying specimens is defined as the ratio of strength of freeze-thaw redrying specimens to the strength of nonimmersed specimens.

\section{Results and Discussion}

4.1. Curing Condition. The purpose of the research on curing condition is to accelerate the curing process of SSGM specimens so as to shorten the curing time and improve the test efficiency. Improvement of the curing temperature is a suitable approach while the final strength is rarely affected. Finally, a curing condition consisting of reasonable curing temperature and curing time is taken as a standard curing condition. Figure 8 shows the unconfined compressive strength and the change curve of curing time of SSGM under different curing temperature conditions. An increase in the curing temperature will greatly reduce the curing time of the test specimens of SSGM. The curing time is significantly reduced from $10 \mathrm{~d}$ to $12 \mathrm{~h}$ when the curing temperature is increased from $30^{\circ} \mathrm{C}$ to $110^{\circ} \mathrm{C}$. However, the unconfined compressive strengths of the specimens under different 


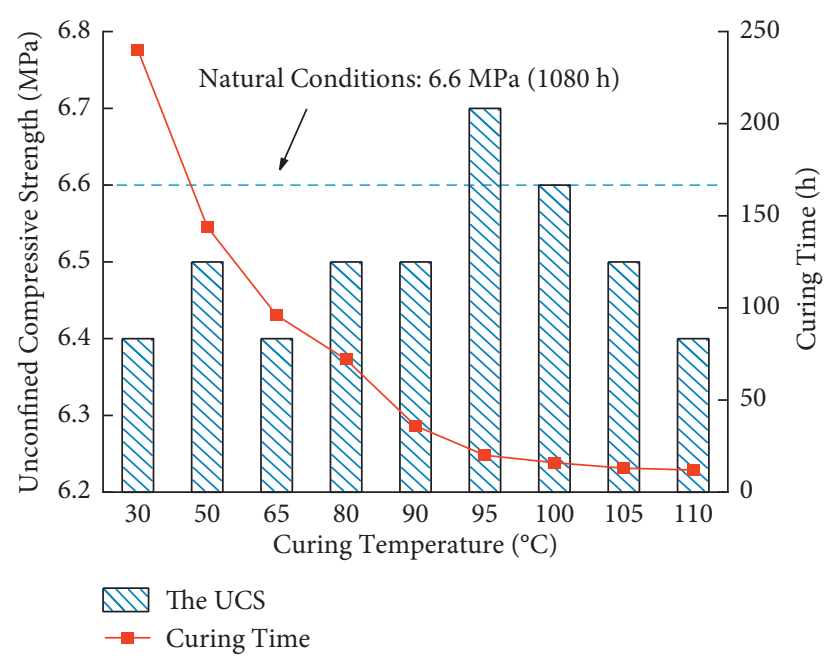

Figure 8: Unconfined compressive strength at different curing temperatures.

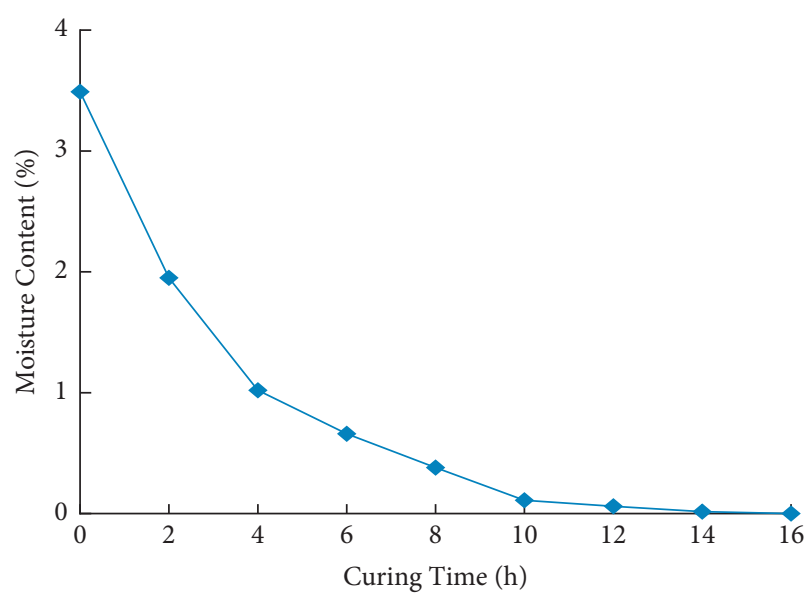

Figure 9: Change of moisture content with curing time.

curing temperatures are slightly different. The strength difference ratio is $1.5 \%-3.0 \%$ by comparing the strength of the specimens cured under the given temperature and the strength (i.e., 6.6 MPa) of the specimens cured for 45 days under natural conditions. Hence, the unconfined compressive strengths of the specimens at different curing temperatures are basically the same as those of specimens cured under natural conditions for 45 days. The curing temperature has little effect on the strength of the specimen under different temperature within a certain temperature range. However, an increase in the curing temperature greatly accelerates the curing process and increases the strength of the specimen. A very high curing temperature causes the materials' aging to a certain extent, considering that SRX stabilizers are organic polymer compounds [17]. The curing temperature of the test specimens should be generally no more than $100^{\circ} \mathrm{C}$ so as to reduce this adverse effect and ensure the accuracy of the test results. Furthermore, considering that lower curing temperature will increase the curing time and reduce the utilization rate of the equipment, the curing temperature should be $100^{\circ} \mathrm{C} \pm 2^{\circ} \mathrm{C}$.
The moisture content, water loss rate, and the dehydration rate of SSGM specimens were taken as the evaluation indexes to further determine the curing time. The variation law of those three indexes with the curing time under the curing temperature of $100^{\circ} \mathrm{C}$ was analyzed. The test results are shown in Figures 9-11. Notably, the water loss rate is defined as the ratio of the difference between the moisture content of test specimen corresponding to an initial state and a certain time state to the moisture content of initial test specimen. The dehydration rate is defined as the ratio of the difference in the moisture content of the test specimen corresponding to a previous and a latter curing time to the curing time interval. The moisture content of the test specimen gradually decreased with an increase in the curing time under a curing temperature of $100^{\circ} \mathrm{C}$. Furthermore, the water loss rate gradually increased and the dehydration rate gradually reduced. In $0-2 \mathrm{~h}$, the dehydration rate of the test specimen was the fastest and the water loss rate in $0 \sim 6 \mathrm{~h}$ was $>80 \%$. Afterwards, the dehydration rate of the test specimen started to slow down. After $10 \mathrm{~h}$, the water loss rate of the test specimen reached $96.8 \%$ and the moisture content reduced to $0.11 \%$, which was close to the dry state. At $16 \mathrm{~h}$, the moisture content of the test specimen was close to 0 and the water loss rate was $100 \%$, indicating that the test specimen was in the dry state. In addition, according to Figure 10, the water loss rate of the test specimen has a good relationship with the curing time. The regression equation is shown as follows:

$$
\omega=0.0539 t^{3}-1.9315 t^{2}+23.31 t+2.0182\left(R^{2}=0.9948\right),
$$

where $\omega$ is the water loss rate of the test specimen and $t$ is the curing time.

The water loss rate of SSGM at any curing time could be determined using (6). When the water loss rate is $100 \%$, the moisture content of the test specimen is zero (i.e., dry state) and the curing time is $15.6 \mathrm{~h}$. Combining Figures 9-11, the curing time is determined as $16 \mathrm{~h}$. In summary, the recommended curing conditions of SSGM are that the curing temperature should be $100^{\circ} \mathrm{C} \pm 2^{\circ} \mathrm{C}$ and the curing time should be $\geq 16 \mathrm{~h}$ in the drying oven.

\subsection{Mechanical Performance}

4.2.1. CBR. Figure 12 shows the CBR values for the SSGM with different SRX stabilizer contents. The CBR value increases with an increase in the SRX content. The CBR value of SSGM is approximately $30 \%$ higher than ordinary graded crushed stone (i.e., the content is $0 \%$ ) under the content of SRX stabilizer of $0.5 \%$. Moreover, the CBR value of SSGM with the content of SRX stabilizer of $1.0 \%$ increases substantially from $446 \%$ to $692 \%$ compared with the ordinary graded macadam. It is obvious that the CBR value of SSGM significantly increases with the SRX stabilizer. Moreover, its CBR value increases with an increase in the content of SRX stabilizer, indicating that SSGM has good bearing capacity. 


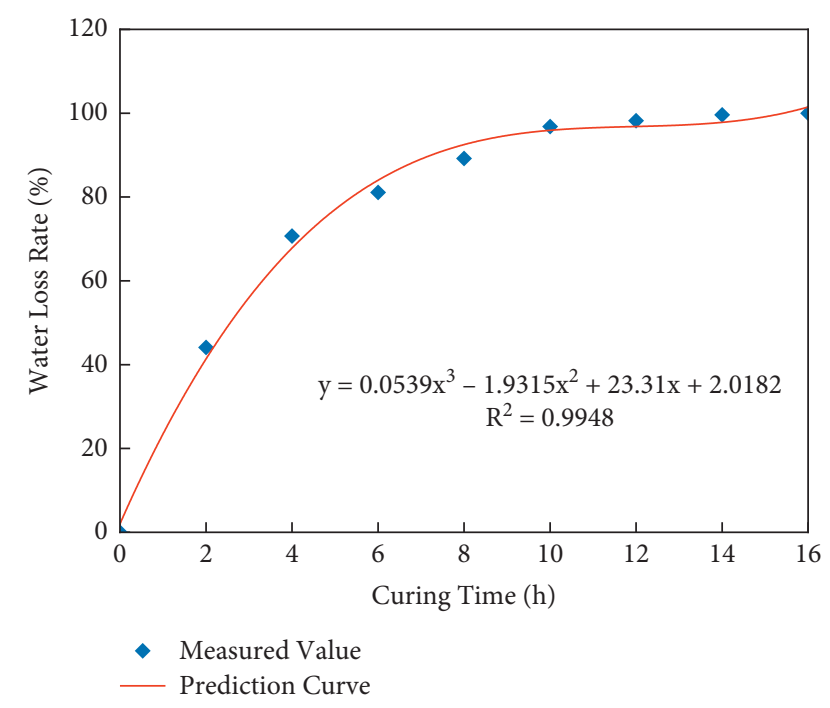

FIgURE 10: Relationship between water loss rate and curing time.

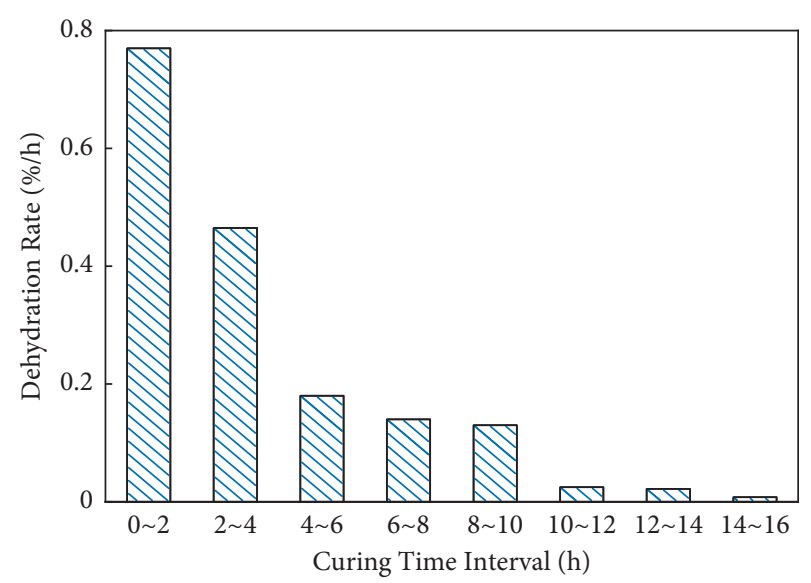

FIgURE 11: Change of dehydration rate with curing time.

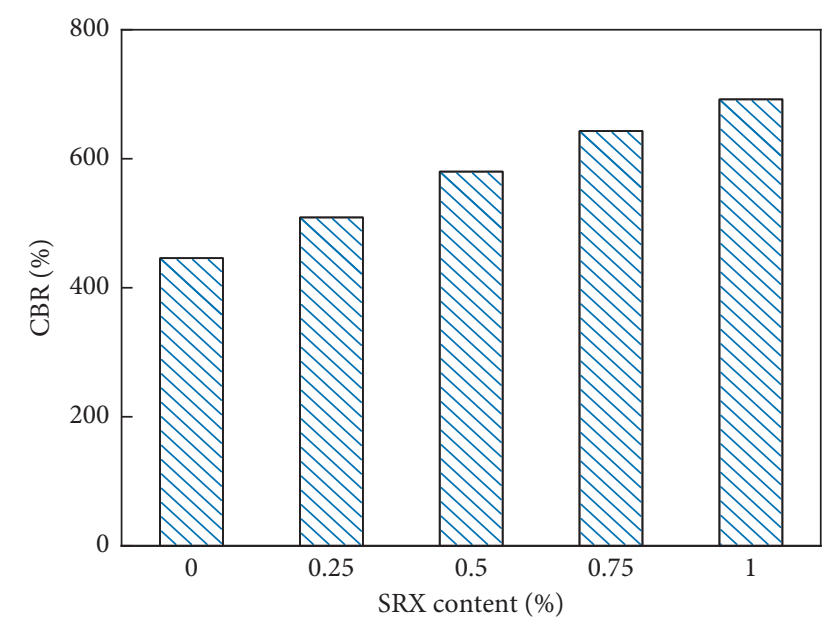

Figure 12: Change law of CBR with SRX content.

4.2.2. Unconfined Compressive Strength and Splitting Strength. Figure 13 shows that the unconfined compressive strength and splitting strength of SSGM gradually increase with an increase in the SRX content. However, the growth rate of the above strength gradually decreases. The unconfined compressive strength increases from 2.52 to $4.71 \mathrm{MPa}$ (an increase of 86.9\%) with an increase in the content of SRX stabilizer from $0.25 \%$ to $1.0 \%$. Meanwhile, the splitting strength increases substantially from 0.15 to $0.31 \mathrm{MPa}$ (an increase of 107\%). Thus, the strength of the graded broken stone increased significantly due to the incorporation of the SRX stabilizer. Under the condition of $0.5 \%$ SRX stabilizer, the unconfined compressive strength of SSGM is approximately 1.64 times larger than that of graded gravel.

4.2.3. Modulus of Resilience. Top surface method was used for the compressive rebound modulus test. Figure 14 shows that the resilient modulus of SSGM increases with an increase in the SRX content. However, the increment gradually decreases. With an increase in the SRX content from $0.25 \%$ to $1.0 \%$, the modulus of resilience increases from 692 to $945 \mathrm{MPa}$, an increase of approximately $37 \%$. Meanwhile, the rebound modulus of SSGM is larger than that of ordinary graded gravel. Under the condition of $0.5 \%$ content, the elastic modulus of SSGM is $814 \mathrm{MPa}$, which is approximately $80 \%$ larger than the graded crushed stone, indicating that SSGM has good resistance to deformation.

\subsection{Pavement Performance}

4.3.1. Temperature Shrinkage Performance. Figure 15 shows the variation of the temperature shrinkage coefficient for different temperature ranges of SSGM. Figure 16 shows the maximum, average, and minimum values of the temperature shrinkage coefficient. The temperature shrinkage coefficient of SSGM increases slightly with an increase in SRX content as shown in Figure 15. In the range of $0--10^{\circ} \mathrm{C}$, the SRX content has the greatest influence (approximately 22\%) on the temperature shrinkage coefficient. Meanwhile, there is a significant difference in the temperature shrinkage coefficient; e.g., the maximum and minimum of the temperature shrinkage coefficient correspond to the temperature ranges of $0^{\circ}--10^{\circ} \mathrm{C}$ and $10-0^{\circ} \mathrm{C}$, respectively. It is indicated that the temperature change has a significant effect on the temperature shrinkage performance of SSGM. Figure 16 shows that the average temperature shrinkage coefficient of SSGM is $4.54-6.18 \times 10^{-6} /{ }^{\circ} \mathrm{C}$. The maximum temperature shrinkage coefficient has a small value of $12.34-15.08 \times 10^{-6} /{ }^{\circ} \mathrm{C}$. As the SRX stabilizer content increases, there is a slight increase in the average temperature shrinkage coefficient and the maximum temperature shrinkage coefficient increases, which indicates that SSGM has good temperature shrinkage performance. To fully analyze the temperature shrinkage properties of SSGM, the average temperature shrinkage coefficient of SSGM and other road materials are presented in Table 4.

Table 4 shows that the temperature shrinkage coefficient of SSGM is much smaller than that of other road materials. Compared with cement-stabilized macadam, the temperature shrinkage coefficient of SSGM is approximately $15 \%$, which indicates that SSGM has good temperature shrinkage 


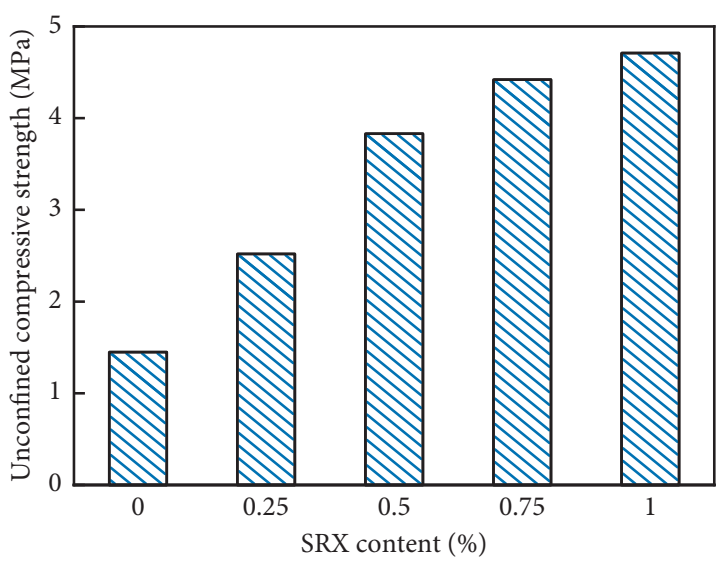

(a)

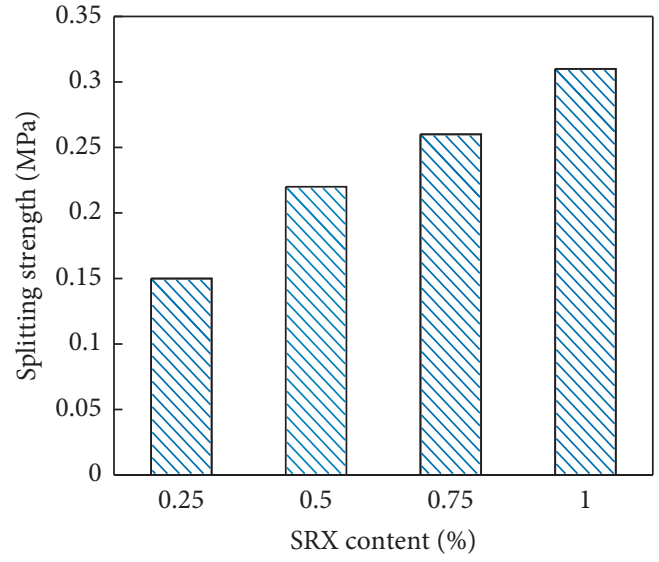

(b)

FIgURE 13: Change law of mechanical strength with SRX content. (a) Unconfined compressive strength. (b) Splitting strength.

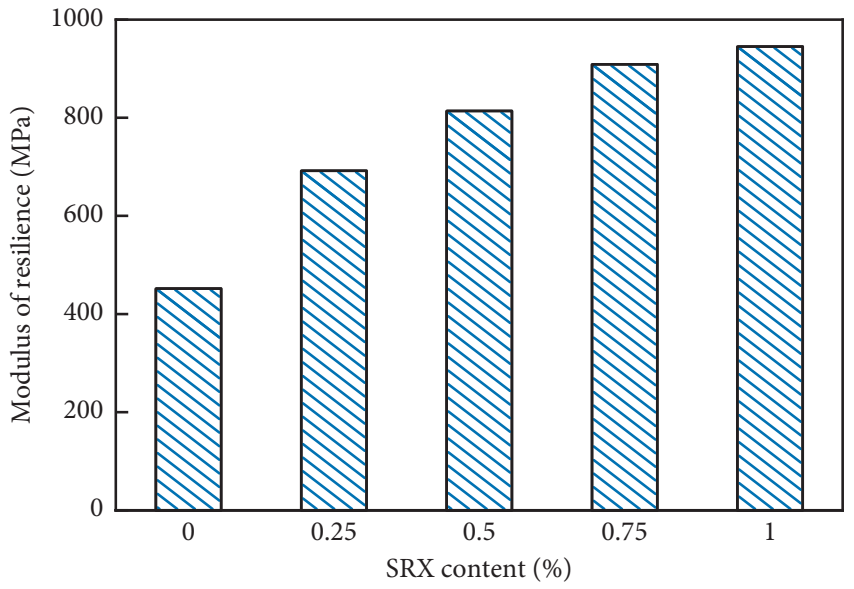

FIgURE 14: Change law of resilient modulus with SRX content.

performance [34-37]. The reflective cracking of asphalt surface caused by shrinkage cracks of semirigid base can therefore be suppressed.

4.3.2. Water Stability Performance. It can be found that the mechanical properties and temperature shrinkage performance of SSGM increase significantly when the content of SRX stabilizer increases from $0.25 \%$ to $0.5 \%$ by referring to the evaluation results of these properties. However, the mentioned properties of SSGM increase gradually when the SRX stabilizer variation contents are $0.5 \%-0.75 \%$ and $0.75 \%-1 \%$, but the increase degree is unobvious. Higher content of SRX stabilizer could induce great increase of economic cost due to the engineering economy. The recommended content of SRX stabilizer is therefore $0.5 \%$.

Table 5 presents the results of the first dry-wet cycling test with compressive and splitting strengths. Figure 17 shows the comparison of the appearance of standard curing specimens (i.e., before the first dry-wet cycle) with the appearance of the redried specimens after the fourth dry-wet cycle. Figures 18 and 19 show the compressive strength after four dry-wet cycling tests.
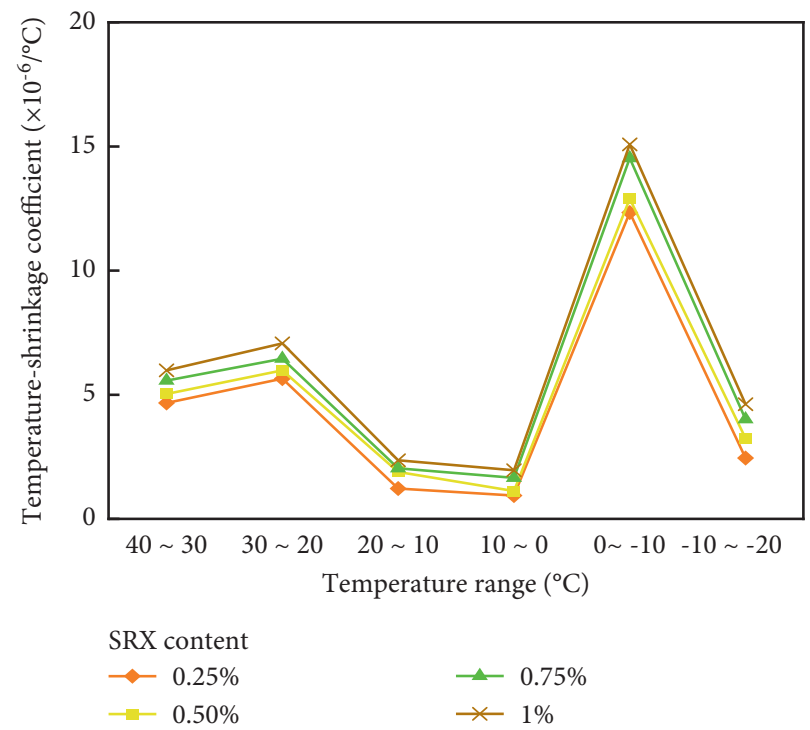

FIGURE 15: Variation of temperature shrinkage coefficient with different SRX stabilizer contents.

Table 5 shows that the softening coefficient of SSGM after the first dry-wet cycle is approximately 55\% while the compressive strength loss is approximately $45 \%$. The strength recovery ratio is $98.36 \%$ after recuring and drying, which indicates that the strength was basically restored.

As can be seen from the comparison of the specimen appearance shown in Figure 17, the surface of the specimens almost remains intact after four dry-wet cycling tests. Furthermore, the weight loss of the specimens is almost zero. The results show that the structures of the specimens are barely destroyed by dry-wet cycles.

The strengths of both immersed and redried specimens decrease with an increase in the dry-wet cycling times as shown in Figures 18 and 19. Meanwhile, the softening coefficient and dry-wet recovery strength ratio slightly decrease, but the reductions of them are gradually narrowed, and the strength of redried specimens has stabilized after the fourth dry-wet cycle. After four dry- 


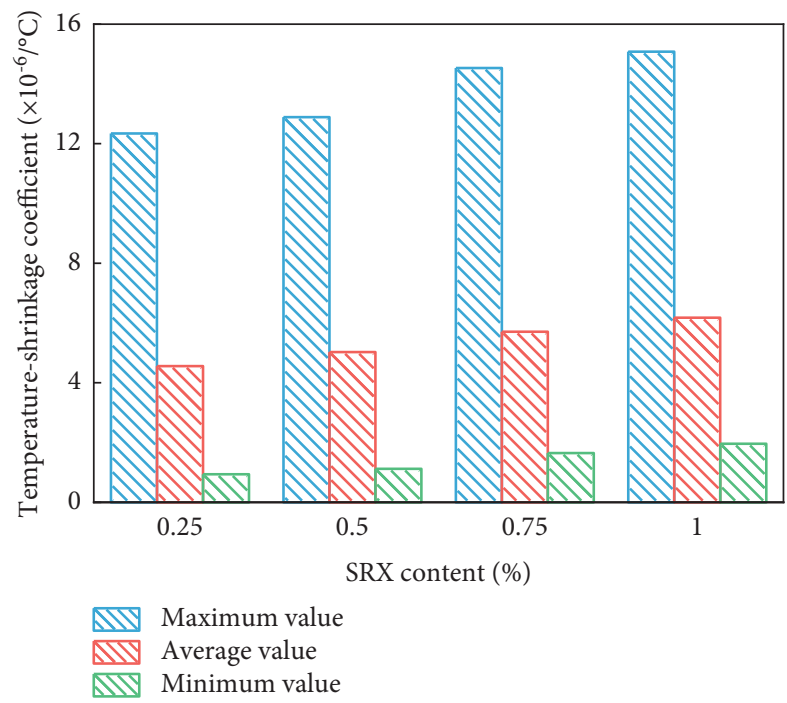

FIgURE 16: The change law of temperature shrinkage coefficient with the content of SRX stabilizer.

TABLE 4: Average temperature shrinkage coefficient of different road materials.

\begin{tabular}{|c|c|c|c|c|c|c|c|c|}
\hline \multirow[t]{2}{*}{ Type } & \multicolumn{4}{|c|}{$\begin{array}{l}\text { SSGM with different } \\
\text { contents }\end{array}$} & \multirow{2}{*}{$\begin{array}{l}\text { Cement } \\
\text { concrete }\end{array}$} & \multirow{2}{*}{$\begin{array}{l}\text { Lime and } \\
\text { gravel soil }\end{array}$} & \multirow{2}{*}{$\begin{array}{l}\text { Lime-fly ash } \\
\text { concrete }\end{array}$} & \multirow{2}{*}{$\begin{array}{l}\text { Skeleton-density cement } \\
\text { stabilized macadam }\end{array}$} \\
\hline & $0.25 \%$ & $0.5 \%$ & $0.75 \%$ & $1 \%$ & & & & \\
\hline $\begin{array}{l}\text { Average temperature shrinkage } \\
\text { coefficient }\left(\times 10^{-6} /{ }^{\circ} \mathrm{C}\right)\end{array}$ & 4.56 & 5.03 & 5.71 & 6.18 & 9.67 & 156 & 56.6 & 37.5 \\
\hline
\end{tabular}

wet cycling tests, the dry-wet recovery strength ratio is 96.4\%; i.e., the strength loss is small (approximately $4 \%$ ). This indicates that the SSGM strength can be restored to the strength of the last test by recuring. This is mainly because water intrusion temporarily softens the organic mucosa formed on the aggregate surface during the drywet cycling test, reducing the bonding strength between SRX and the aggregate such that the structure is rarely destroyed. When the moisture is removed again, the bonding strength between aggregates is perfectly restored. This shows that dry-wet cycling will not damage SSGM and it is reasonable and feasible to use the dry-wet recovery strength ratio to evaluate water stability. The SSGM has good water stability performance on the basis of the comprehensive evaluation of softening coefficient and dry-wet recovery strength ratio. However, more attention should be paid to drainage design in order to better develop the performance of materials due to the low softening coefficient of SSGM.

To sum up, the strength of SSGM is barely reduced after four dry-wet cycle tests. The unconfined compressive strengths of both the immersed and the redried specimens are basically unchanged after the third and fourth dry-wet cycle tests. This shows that the unconfined compressive strength of SSGM specimens basically reaches a stable state. It is therefore an optional strategy that the number of the dry-wet cycles is four. The dry-wet cycling test is performed based on the given number of the dry-wet cycles.
4.3.3. Freezing Stability Performance. The specimen used in freeze-thaw cycle tests is the same as that of dry-wet cycle tests. Table 6 lists the test results of the unconfined compressive strength and splitting strength after the first freezethaw cycle. Figures 20 and 21 show the unconfined compressive strength of each freeze-thaw cycle. Figure 22 shows the comparison of the appearance of standard curing specimens (i.e., before freeze-thaw cycle) and the redried specimens after the fifth freeze-thaw cycle.

Table 6 shows that the freeze-thaw coefficient of SSGM after the first freeze-thaw cycle is approximately $86 \%$, which is mainly related to the strength reduction (approximately $45 \%$ ) after immersion. Moreover, the freeze-thaw recovery strength ratio after recuring is approximately $90 \%$, which is smaller than the dry-wet recovery strength ratio after the first dry-wet cycle; however, the strength after the first freeze-thaw cycle can be greatly recovered. It can be seen that the freezing stability performance of SSGM is hardly weakened after the first freeze-thaw cycle.

As shown in Figures 20 and 21, with the number of freeze-thaw cycles increasing, the strength of the SSGM, the freeze-thaw coefficient, and the freeze-thaw recovery strength ratios decreased continuously and gradually. After five freeze-thaw cycles, the freeze-thaw coefficient is only $51 \%$ and the freeze-thaw recovery strength ratio is approximately $58 \%$, indicating that the strength loss is very serious. The main reasons are as follows: the bonding force between SRX and the aggregate is reduced; the organic 
TABLE 5: Water stability performance of SSGM.

\begin{tabular}{|c|c|c|c|c|c|c|}
\hline Indexes & $\begin{array}{l}\text { Strength of unsoaked } \\
\text { specimens }(\mathrm{MPa})\end{array}$ & $\begin{array}{l}\text { Strength of soaked } \\
\text { specimens }(\mathrm{MPa})\end{array}$ & $\begin{array}{c}\text { Softening } \\
\text { coefficient (\%) }\end{array}$ & $\begin{array}{l}\text { Strength of soaked and } \\
\text { redried specimens } \\
(\mathrm{MPa})\end{array}$ & $\begin{array}{l}\text { Loss } \\
\text { strength } \\
(\mathrm{MPa})\end{array}$ & $\begin{array}{c}\text { Recovery } \\
\text { strength ratio } \\
(\%)\end{array}$ \\
\hline $\begin{array}{l}\text { Compressive } \\
\text { strength }\end{array}$ & 6.72 & 3.83 & 56.99 & 6.61 & 0.11 & 98.36 \\
\hline $\begin{array}{l}\text { Splitting } \\
\text { strength }\end{array}$ & 0.41 & 0.22 & 53.66 & 0.40 & 0.01 & 97.56 \\
\hline
\end{tabular}

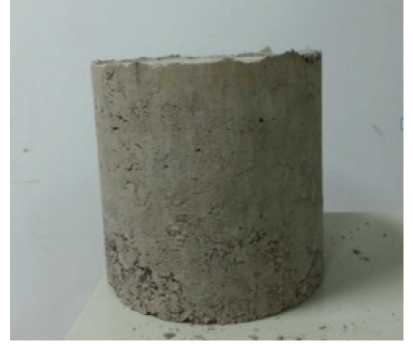

(a)

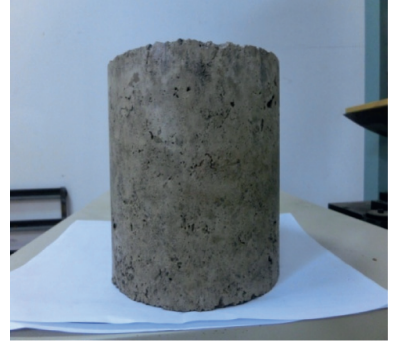

(b)

Figure 17: Appearance of the test specimen (a) before and (b) after dry-wet cycling. (a) Standard curing specimen. (b) Specimen of the fourth dry-wet cycling test.

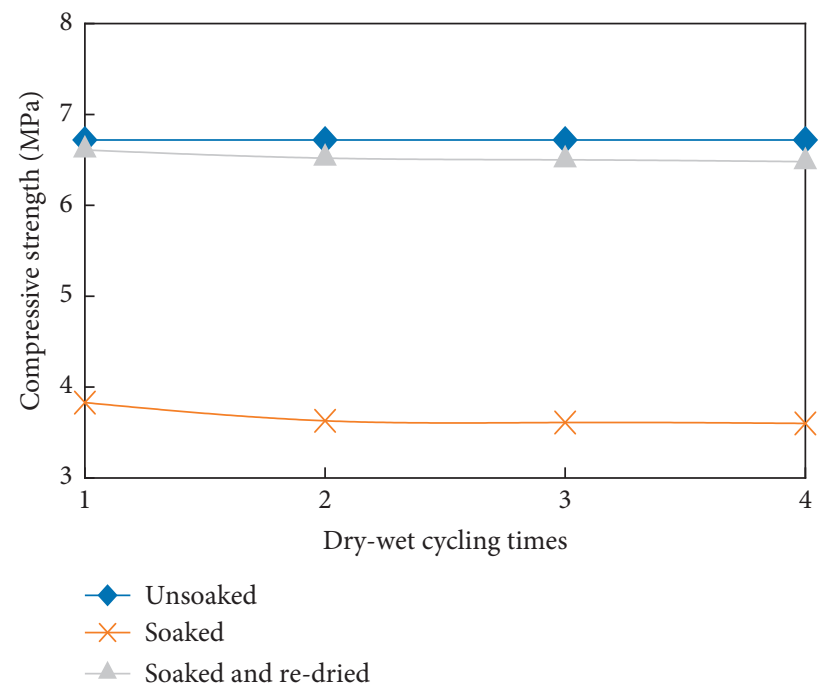

Figure 18: Compressive strength change law of different dry-wet cycles.

mucous membrane formed on the aggregate surface is damaged; the structure of SSGM is destroyed; the strength is not completely recovered after recuring. Freeze-thaw cycles cause permanent cumulative damage to SSGM. The damage degree of freezing stability performance of SSGM increases with the number of freeze-thaw cycles.

The damage of the specimens is not obvious after five freeze-thaw cycles from the appearance of specimens presented in Figure 22. The edge and corner of the specimens are damaged slightly. It can be seen that the spalling is not significant. Considerable attention should be therefore paid toward the antifreezing protection engineering in cold and frozen areas to avoid the impact of freezing and thawing on the freezing stability performance of SSGM structure layer.
The increase in the content of SRX stabilizer can improve the freezing stability performance of SSGM. Figure 23 shows the results of the fifth freeze-thaw cycle test of SSGM with different contents.

As shown in Figure 23, the freeze-thaw coefficients and recovery strength ratios increase to varying degrees as the SRX stabilizer content increases. After five freezethaw cycles, when the SRX stabilizer content increases from $0.25 \%$ to $1.0 \%$, the freeze-thaw coefficient increases from $41.6 \%$ to $68.4 \%$, an increase of $64.5 \%$; and the freezethaw recovery strength ratio increased from $47.7 \%$ to $73.2 \%$, an increase of approximately $25.5 \%$. The freezethaw stability was considerably improved, which indicates that an increase in the SRX stabilizer content 


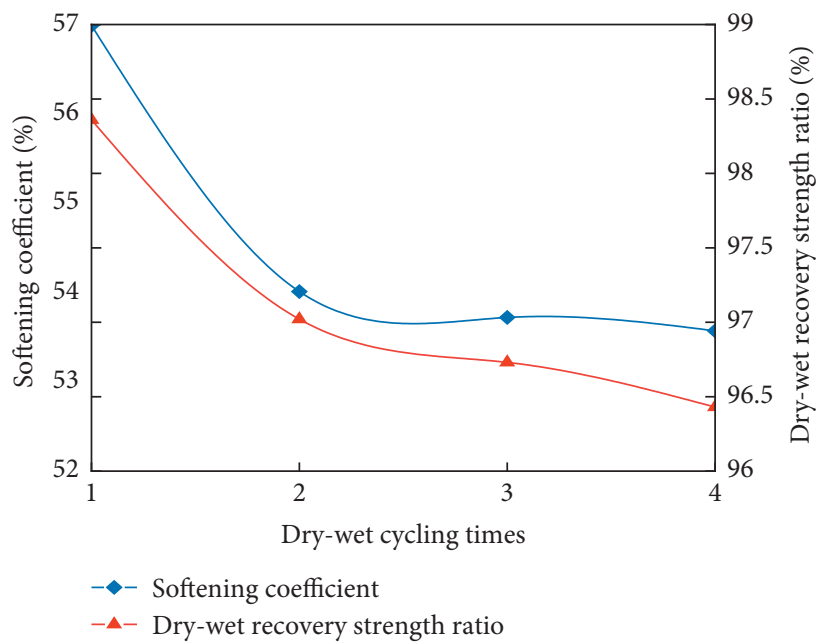

FIGURE 19: . Softening coefficient and dry-wet recovery strength ratio at different dry-wet cycles.

TABLE 6: Freezing stability performance of SSGM after the first freeze-thaw cycle test.

\begin{tabular}{lcccccc}
\hline Indexes & $\begin{array}{c}\text { Strength of } \\
\text { immersed } \\
\text { specimen (MPa) }\end{array}$ & $\begin{array}{c}\text { Strength of } \\
\text { freeze-thaw } \\
\text { specimen (MPa) }\end{array}$ & $\begin{array}{c}\text { Freeze-thaw } \\
\text { coefficient (\%) }\end{array}$ & $\begin{array}{c}\text { Strength of } \\
\text { nonimmersed } \\
\text { specimen (MPa) }\end{array}$ & $\begin{array}{c}\text { Strength of } \\
\text { redried } \\
\text { specimen } \\
(\mathrm{MPa})\end{array}$ & $\begin{array}{c}\text { Loss } \\
\text { strength } \\
(\mathrm{MPa})\end{array}$ \\
$\begin{array}{l}\text { Compressive } \\
\text { strength }\end{array}$ & 3.83 & 3.32 & 86.68 & 6.72 & 6.04 & 0.68 \\
\hline $\begin{array}{l}\text { Splitting } \\
\text { strength }\end{array}$ & 0.22 & 0.19 & 86.36 & 0.41 & 0.36 & 8.05 \\
\hline
\end{tabular}

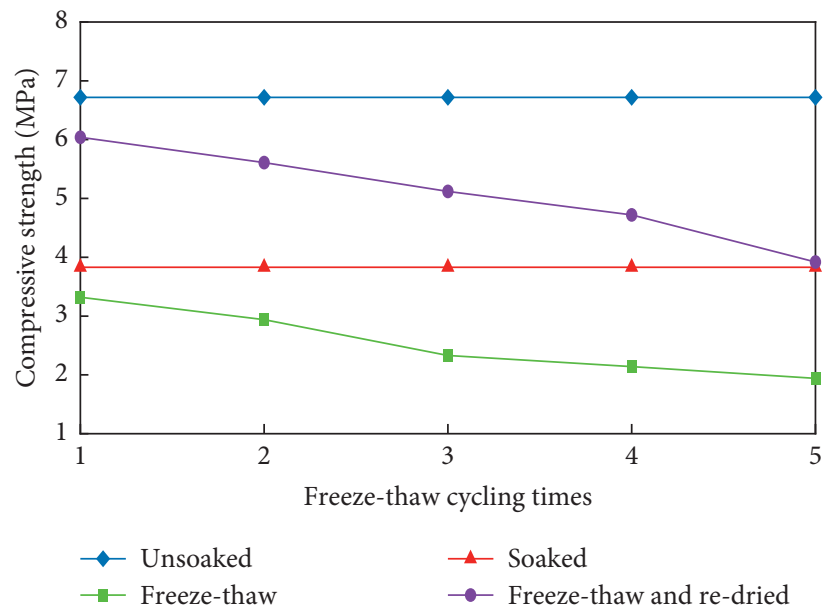

Figure 20: The unconfined compressive strength of specimens under different freeze-thaw cycles.

increased the thickness of SRX organic mucosa formed on aggregate surface and the ability to resist freeze-thaw damage was strengthened. The increase in the SRX stabilizer content properly is therefore helpful to promoting the freeze-thaw resistance of the SSGM base. In cold and frozen areas, the content of the SRX stabilizer should be increased appropriately to a recommended value of $0.75 \%$. 


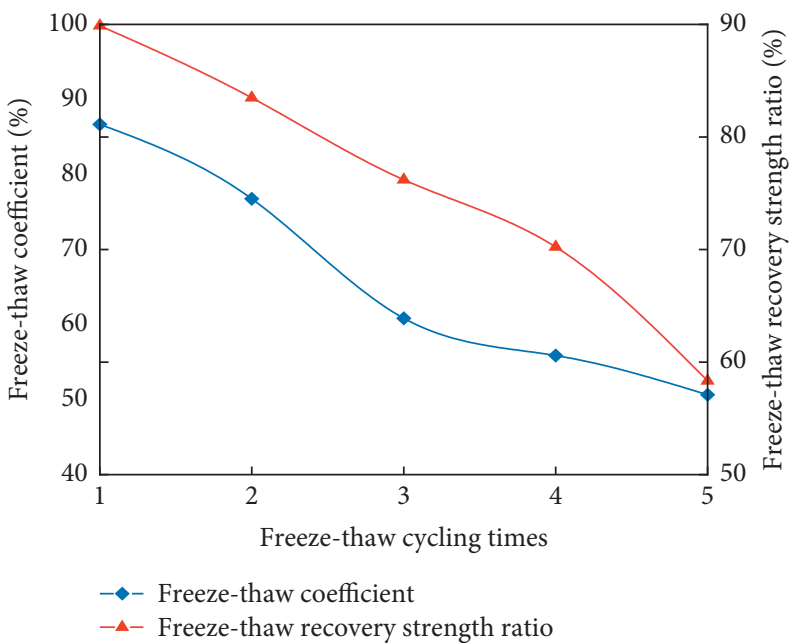

Figure 21: Freeze-thaw coefficient and recovery strength under different freeze-thaw cycle ratios under different freeze-thaw cycles.

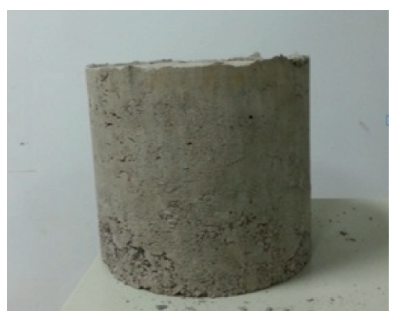

(a)

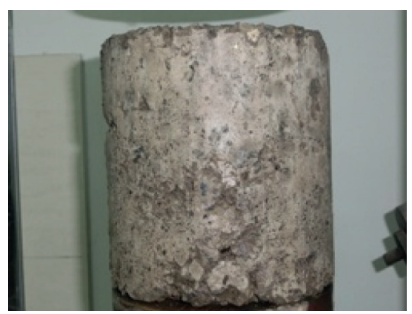

(b)

Figure 22: Appearance of test specimen (a) before and (b) after the freeze-thaw cycle. (a) Standard curing specimen. (b) Specimen after the fifth freeze-thaw cycle.

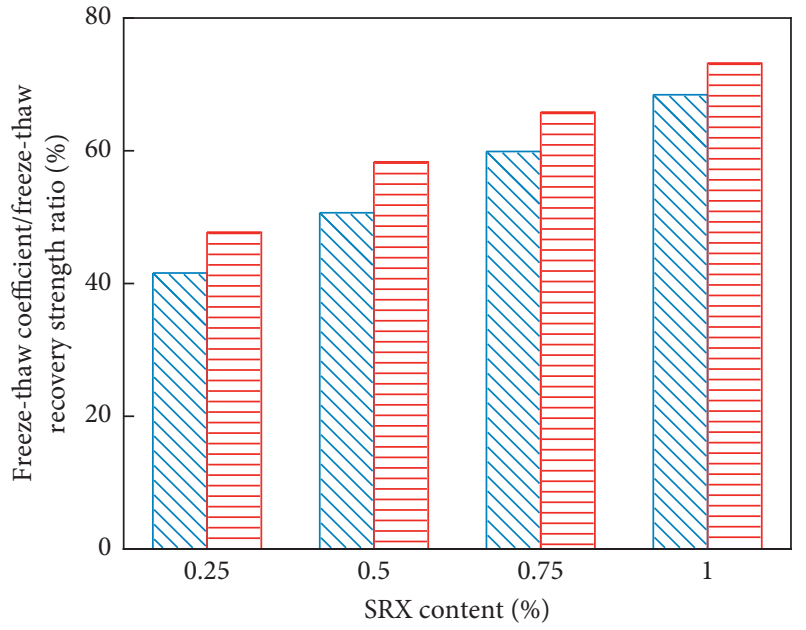

N1V Freeze-thaw coefficient
$\equiv$ Freeze-thaw recovery strength ratio

Figure 23: Freeze-thaw coefficient and freeze-thaw recovery strength ratio of different stabilizer contents.

\section{Conclusion}

This study focused on the investigation on the technical performances of SSGM. The curing conditions were first developed. The CBR value, strength, resilient modulus, temperature shrinkage performance, water stability performance, and freezing stability were then analyzed under different contents of SRX stabilizer. Furthermore, a reasonable range of SRX stabilizer content was proposed. The following conclusions may be drawn:

(1) The effect of curing temperature on unconfined compressive strength of SSGM is insignificant. Further increase in curing temperature will have little effect on the final strength of SSGM even if the curing temperature is $110^{\circ} \mathrm{C}$. However, the increase in curing temperature can significantly accelerate the curing process of SSGM in laboratory test. The curing temperature of SSGM should be controlled to approximately $100^{\circ} \mathrm{C}$ to avoid the aging of SRX stabilizer due to excessive temperature. The water loss rate of the specimen gradually increases with an increase in the curing time at a curing temperature of $100^{\circ} \mathrm{C}$. The curing time was $16 \mathrm{~h}$ when the moisture content is zero and the water loss rate is $100 \%$. The recommended curing conditions of SSGM specimens are therefore as follows: the curing temperature should be $100^{\circ} \mathrm{C} \pm 2^{\circ} \mathrm{C}$; the curing time should not be less than $16 \mathrm{~h}$ in the drying oven.

(2) SSGM has good mechanical performances. As the SRX content increased, the mechanical properties 
significantly improved. When the SRX content was in the range of $0.25 \%-1 \%$ and increased by $0.25 \%$, the unconfined compressive strengths under the condition of vibration forming were $52 \%, 15 \%$, and $7 \%$ higher than the previous ones. Furthermore, the splitting strengths increased by $47 \%, 18 \%$, and $19 \%$ while the compressive resilient modulus increased by $18 \%, 12 \%$, and $4 \%$. Moreover, CBR increased by $14 \%, 11 \%$, and $8 \%$. Meanwhile, the growth range reduced as the SRX content increased. When the SRX content was $0.5 \%$, the CBR value, unconfined compressive strength, and modulus of resilience of the SSGM were significantly improved compared with ordinary graded macadam.

(3) The pavement performances of SSGM were analyzed from three aspects. (1) The temperature shrinkage coefficient varies greatly in different temperature ranges, especially in the range of $0^{\circ} \mathrm{C}--10^{\circ} \mathrm{C}$ (maximum temperature shrinkage coefficient) and $10^{\circ} \mathrm{C}-0^{\circ} \mathrm{C}$ (minimum temperature shrinkage coefficient). It is indicated that the temperature has a significant effect on temperature shrinkage coefficient. Additionally, temperature shrinkage coefficient of SSGM is much smaller than that of other pavement stabilized materials such as cement concrete, lime and gravel soil, lime-fly ash concrete, and skeleton-density cement-stabilized macadam, so SRX has excellent temperature shrinkage resistance. The application of SSGM between asphalt layer and semirigid base layer can therefore effectively restrain reflective cracks in these pavements caused by the shrinkage cracks in semirigid base. (2) The water stability of SSGM is evaluated using softening coefficient and dry-wet recovery strength ratio. The results show that SSGM can effectively resist damage caused by dry-wet cycling. The invasion of water just reduces the strength temporarily and has rare impact on the internal structure of SSGM. The strength also can basically return to the original state when the specimen is redried. It can be considered that SSGM has good water stability performance. (3) The freeze-thaw stability of SSGM is characterized using the freeze-thaw coefficient and recovery strength ratio. The obtained freeze-thaw coefficient and recovery strength ratio are small while the recovery strength ratio is only approximately 58\% after five freeze-thaw cycles. The recovery strength ratio of $58 \%$ indicates that five freeze-thaw cycles cause serious damages to SSGM. It is observed that an increase in the SRX content caused a significant improvement in the freezing stability of the SRX through the contrast test of strength of SSGM with different SRX stabilizer content after five freeze-thaw cycles. Increase in the strength and stability of SSGM is considerably obvious under the condition of $0.5 \%-0.75 \%$ SRX content. The strength and bearing capacity of SSGM fulfill the technical requirements under the condition of $0.75 \%$ SRX content.

(4) The reasonable content of SRX is determined by comprehensively analyzing the effect of the content of SRX stabilizer on mechanical properties and pavement performances. It is recommended that the SRX stabilizer content is $0.5 \%$ under common conditions, and its content should be $0.75 \%$ in cold and frozen areas.

(5) A certain understanding of technical performances of SSGM is given in this paper, but some extra works need to be further investigated. For instance, more relevant properties tests should be conducted to provide a better understanding of technical performances of SSGM. Investigation on the application of field engineering regarding SSGM should be therefore performed based on the above more relevant properties tests and the properties tests preformed in this paper. In general, more relevant properties tests will be first conducted, and then field engineering is performed to optimize the conclusions drawn in this paper in future study.

\section{Data Availability}

The data and materials are included within the article.

\section{Conflicts of Interest}

The authors declare that they have no conflicts of interest.

\section{Acknowledgments}

The authors gratefully acknowledge the support of test conditions from Key Laboratory for Special Area Highway Engineering of Ministry of Education.

\section{References}

[1] A. M. Sha, "Material characteristics of semi-rigid base," China Journal of Highway and Transportation, vol. 21, no. 1, pp. 1-5, 2008, in Chinese.

[2] X. Zhao, A. Sha, and B. Hong, "Mechanical analysis of vaulted expansion of semi-rigid base," Journal of Highway and Transportation Research and Development, vol. 3, no. 2, pp. 54-58, 2008.

[3] Q. Xu, J. Bian, and S. Meng, "Study of flexible base and semirigid base asphalt pavement performance under accelerated loading facility (ALF)," in Proceedings of Apt 08 Third International Conference, Madrid, Spain, October 2008.

[4] L. Q. Hu, Research on Structural Characteristic and Component Design Methods for Semi-Rigid Base Course Material, Chang'an University, Xi'an, China, 2004, in Chinese.

[5] Z. F. Li, G. N. Xu, and X. Y. Guo, "Asphalt pavement structure with semi-rigid base course based on cross-anisotropy," Journal of Chang'an University (Natural Science Edition), vol. 6, pp. 21-24, 2008, in Chinese.

[6] S. Ping, L. Jiang, A. Shen, and X. Liu, "Research on adaptability of semi-rigid material as base course for long-life asphalt pavement," Journal of Highway and Transportation Research and Development, vol. 4, no. 2, pp. 11-14, 2010.

[7] W. G. Wong, Y. Qun, and K. C. P. Wang, "Performances of asphalt-treated base and semi-rigid base," HKIE Transactions, vol. 10, no. 3, pp. 54-58, 2003.

[8] C. F. Yang, H. R. Pi, T. Xiao, and C. Z. Jin, "Mechanical response analysis of heavy traffic on semi-rigid base pavement performance," Applied Mechanics and Materials, vol. 97-98, pp. 146-150, 2011. 
[9] J. Zheng, "Design guide for semirigid pavements in China based on critical state of asphalt mixture," Journal of Materials in Civil Engineering, vol. 25, no. 7, pp. 899-906, 2013.

[10] G. F. Li, C. H. Chen, B. F. Jiang, and L. Y. Su, "Mechanics analysis of flexible base pavement structure," Applied Mechanics and Materials, vol. 580-583, pp. 632-635, 2014.

[11] R. B. Ren, H. W. Li, and Z. R. Wang, "Analysis of semi-rigid asphalt pavement with flexible base as a sandwich layer," in Proceedings of Selected Papers from the Geohunan International Conference, August 2009.

[12] K. A. Khaled, "Performance-based models for flexible pavement structural overlay design," Journal of Transportation Engineering, vol. 131, no. 2, pp. 149-159, 2005.

[13] S. Meng and X. Huang, "Study on optimum design of mixture for asphalt pavement with flexible base," Journal of Highway and Transportation Research and Development, vol. 1, no. 1, pp. 1-5, 2006

[14] L. Cao, Z. Dong, and Y. Tan, "Design and performance evaluation of cold recycled mixture with emulsified asphalt," Journal of Highway and Transportation Research and Development, vol. 1, no. 1, pp. 15-22, 2006.

[15] C. Guo, N. Wang, H. Ruan, Q. Shen, and G. Wang, "Mechanical analysis of asphalt pavements with a graded crushed stone base under dynamic load," Journal of Highway and Transportation Research and Development, vol. 10, no. 4, pp. 13-20, 2016.

[16] M. Zhang, L. Wang, and Y. Zhou, "Asphalt pavement structure analysis of the upper base of the graded crushed stone," Journal of Shenyang Jianzhu University Natural Science, vol. 27, no. 1, pp. 64-69, 2011, in Chinese.

[17] L. H. He, W. Deng, and H. Z. Zhu, "Propreties of SRX waterbased polymer materials," Applied Chemical Industry, vol. 49, no. 4, pp. 93-96, 2008, in Chinese.

[18] Y. Zhang, Y. L. Zhao, and B. Y. Yu, "The study on road performance and pavement structure analysis for the base layer material stabilized by SRX," Advanced Materials Research, vol. 594-597, pp. 1402-1406, 2012.

[19] Romix International Ltd, Design Criteria for Road Water Based polymer (SRX-VR Series) Flexible Road Structures, China Communications Press, Beijing, China, 2010, in Chinese.

[20] S. R. Iyengar, E. Masad, A. K. Rodriguez, and H. S. Bazzi, "Pavement subgrade stabilization using polymers: characterization and performance," Journal of Materials in Civil Engineering, vol. 25, no. 4, pp. 472-483, 2013.

[21] E. J. Scholten, W. Vonk, and J. Korenstra, "Towards green pavements with novel class of SBS polymers for enhanced effectiveness in bitumen and pavement performance," International Journal of Pavement Research and Technology, vol. 3, no. 4, pp. 216-222, 2010.

[22] M. J. Zhang, Y. L. Zhao, B. Y. Yu, and P. D. Ou, "Hydroradical polymer stabilized base materials mechanics properties and pavement structure analysis," Journal of Shenyang Jianzhu University Natural Science, vol. 28, no. 6, pp. 10301036, 2012, in Chinese.

[23] H. X. Du, The Experimental Study of Flexible Base Stabilized by SOILFIX Polymer, Beijing Architecture University, Beijing, China, 2011, in Chinese.

[24] China Communications Press, JTG E42-2005. Test Methods of Aggregate for Highway Engineering, China Communications Press, Beijing, China, 2005, in Chinese.

[25] China Communications Press, JTG/T F20-2015. Technical Guidelines for Construction of Highway Roadbases, China Communications Press, Beijing, China, 2015, in Chinese.
[26] X. D. Yang, L. Ma, and Z. Q. Zhang, "Effect of particles size of coarse aggregate on stability of aggregate blend," Journal of Xi'an University of Science and Technology, vol. 26, no. 4, pp. 480-484, 2006, in Chinese.

[27] D. Li, Research on Graded Broken Stone Design Standard and Design Method Based on Vibrating Compaction, Chang'an University, Xi'an, China, 2013, in Chinese.

[28] J. L. Zhang, Study on the Test of Vibratory Compaction for Cement Stabilized Gravel, Chang'an University, Xi'an, China, 2008, in Chinese.

[29] Y. Jiang, J. Xue, and Z. Chen, "Influence of volumetric property on mechanical properties of vertical vibration compacted asphalt mixture," Construction and Building Materials, vol. 135, pp. 612-621, 2017.

[30] China Communications Press, JTG E40-2007, Test Method of Soils for Highway Engineering, China Communications Press, Beijing, China, 2007, in Chinese.

[31] China Communications Press, JTG E51-2009, Test Methods of Materials Stabilized with Inorganic Binders for Highway Engineering, China Communications Press, Beijing, China, 2009, in Chinese.

[32] Q. Hu and M. Sha, "Research on influence factor in semi-rigid base course material temperature shrinkage coefficient test using strain gauge," Journal of Highway and Transportation Research and Development, vol. 2, no. 2, pp. 12-15, 2007.

[33] C. Wang, Z. Fan, and C. Li, "Preparation and engineering properties of low-viscosity epoxy grouting materials modified with silicone for microcrack repair," Construction and Building Materials, vol. 290, Article ID 123270, 2021.

[34] P. Jitsangiam and H. Nikraz, "Mechanical behaviours of hydrated cement treated crushed rock base as a road base material in Western Australia," International Journal of Pavement Engineering, vol. 10, no. 1, pp. 39-47, 2009.

[35] Y. Wang and X. Sun, "Research on the shrinkage performance of cement-stabilized base," Advanced Materials Research, vol. 905, pp. 292-295, 2014.

[36] Y. J. Yingjun Jiang, L. W. Liwei Li, J. L. Jiaolong Ren, Y. S. Yinshan Xu, and Y. Yi Zhang, "Performances of cementstabilized macadam with multilevel dense built-in grading structure gradation," in Proceedings of International Conference on Electric Technology \& Civil Engineering, April 2011.

[37] J. Cheng, Z. Xu, and Z. Sun, "Trial research on cement-stabilized macadam anti-crack evaluation coefficient based on environment and load," Journal of Highway and Transportation Research and Development, vol. 4, no. 1, pp. 7-11, 2009. 